\title{
Duodenal obstruction in donkeys (An experimental study)
}

\author{
M. M. Seif ${ }^{1}$, S. A. Ahmad ${ }^{2}$, G. H. Ragab ${ }^{1}, H . H . k^{2}$ Kal $^{3}$, \\ M. S. Aimen ${ }^{1}$ \\ ${ }^{1}$ Department of Surgery, Anesthesiology and Radiology, Beni Suef University, Egypt \\ ${ }^{2}$ Department of Surgery, Anesthesiology and Radiology, Cairo University, Giza, Egypt \\ ${ }^{3}$ Department of clinical pathology, Beni-Suef University, Egypt
}

\begin{abstract}
An experimental study was conducted on 14 donkeys. The animals were classified into two main groups. The first group included 5 donkeys that are used for induction of duodenal, obstruction for determination of the different clinical and biochemical changes and for determination of the mean survival time after obstruction. The second group contained 9 donkeys that were used for the determination of proper time for surgical intervention. Results revealed that mean survival time after obstruction was 20-35 $\mathrm{h}$ and the critical time for surgery was 14-35 $\mathrm{h}$.
\end{abstract}

Equine colic encompasses various pathophysiologic processes that threaten animal life. The high incidence of mortality in animals suffered from colic is related to the severity of gastrointestinal disorders and to the nature of the symptomatic disorders such as endotoximic shock, electrolyte imbalance, vascular collapse or disseminated intervascular coagulation (White et al., 1980 and More and White, 1982). Freeman (1999) mentioned that $25-64 \%$ of all colic cases involved the small intestine, of these cases, $58 \%$ were caused by strangulating lesions and $42 \%$ were due to simple obstruction. (Blood et al., 1995 and Snyder and Spier, 1996) mentioned that strangulating obstruction is more dangerous disease than simple obstruction and the course of the diseases is usually very short when compared with simple obstruction. Treatment of colic varies greatly according to the nature, locaction and duration of the disease. Most of large animal practitioners successfully diagnosed and treated the majority of the complicated cases of colic. However, a frustrating situation arises when one has to decide whether conservative or surgical therapy is indicated, or if euthanasia is advised (Morris, 1987).

Therefore this work aims to determine the mean survival time after experimentally induced complete simple obstruction of the duodenum. The different clinical and biochemical changes and the proper time for surgical intervention were investigated in order to achieve maximal survival rate in donkeys.

\section{Material and methods}

Fourteen, 8-13 years old adult donkeys of about 200-250 kg weight, were used in this study. The animals were divided into two main groups: Group I (5 animals) was used for induction of complete duodenal obstruction mean survival time, clinical and biochemical changes after obstruction, Group II (9 animals) was used to determine the maximal survival rate after obstruction and surgical treatment by anastomosis.

Induction of duodenal obstruction. Obstruction device consisted of Rayel's tube No. 10, rubber hose 30-40 cm length and $1 \mathrm{~cm}$ internal diameter was used.

Animal preparation. Food and water were withheld for $12 \mathrm{~h}$ before surgery and animals were narcotized with chloral hydrate $5 \mathrm{gm} / 50 \mathrm{~kg}$ $10 \%$ i.v. with local linear infiltration anesthesia using lidocaine $2 \%$ at the site of incision. The animals were positioned in lateral recumbency and prepared for aseptic surgery.

Surgical procedures. Ventral right flank laparotomy (Fig. 1,2) was performed according to Voughen (1972). The duodenum was located close to the right kidney and exteriorized (Fig. 3 ). The mesentery was punctured close to the duodenum, through which the Rayel's tube was threaded and encircled the duodenum (Fig. 4). The created loop of Rayel's tube was sutured close to the duodenum by silk No. 0 forming a ring around it (Fig. 5). The two free ends of the Rayel's tube were threaded into the rubber hose and fixed in it by suturing using silk No. 0 . The hose containing the Rayel's tube was passed through the muscular incision in the abdominal wall and fixed subcutaneously (Figure 6). The abdominal wall was closed in standard manner (Fig. 7). The animals were injected with penicillin streptomycin $2 \mathrm{gm}$ i.m. twice daily for 
three successive days and were gradually returned to full feed over the next $24 \mathrm{~h}$.

Two weeks later, apparently healthy animals were subjected to surgery, $2 \mathrm{~cm}$ skin incision was made at the site of the fixed Rayel's tube and the stitches fixing the tube were removed. The Rayel's tube was grasped against the hose to induce complete simple obstruction and the tube was fixed to the hose by hemostatic forceps (Fig. 8).

Animals that have clinical signs of abdominal pain were examined every $2 \mathrm{~h}$ up to death for attitude, pulse, respiration rate and rectal temperature. For biochemical analysis, gastric juice and blood samples were collected directly before induction of obstruction, 1 hour, 2 hours and every two hours till death of the animal.

Postmortem examination of dead animals was performed. Biopsy specimens were taken oral to the site of ligation and were kept in $10 \%$ formalin for histopathological examination. The survival time of each animal was recorded.

Resection and anastomosis. Animals of group II were prepared for duodenal obstruction by the previously manner mentioned. Surgical interference was performed before the calculated mean of survival time of $2 \mathrm{~h}$ ( 3 animals), $4 \mathrm{~h} \mathrm{(3}$ animals), and $6 \mathrm{~h}$ (3 animals) respectively.

Animals were prepared for aseptic surgery, narctotised by i.v. $10 \%$ aqueous solution of chloral hydrate at dose of $5 \mathrm{gm} / 50 \mathrm{~kg}$. Nasogastric tube was inserted into the stomach for gastric decompression. Laparotomy at the right flank was performed. The Rayel's tube and the hose were removed and the duodenum was grasped gently (Fig. 9). The obstructed loop was isolated by ligation anterior and posterior to the site of obstruction using Vicryl No. 0 (Fig.10). The mesenteric vessels were isolated and double ligated with 0 polyglycolic acid. A small portion of the duodenum (about $2 \mathrm{~cm}$ ) was resected at 50-60 degree from the anti-mesenteric border (Fig. 11). The resected ends of the duodenum were anastomosed by two apposition stitches at the mesenteric and anti-mesenteric surfaces (Fig. 12). Then the two ends were sutured by simple interrupted layer (Fig. 13), followed by single layer of continous inverting cushing suture (without mucosal involvement) using cat gut no 3/0 (Fig. 14).

Postoperation care. After surgery the animals were maintained on ringer lactate $5 \mathrm{~L} / 100 \mathrm{~kg}$ i.v., with infusion rate of $400 \mathrm{ml} / 100 \mathrm{~kg} / \mathrm{h}$, Neostigmine methyl sulfate $0.01 \mathrm{mg} / \mathrm{kg}$ s.c. solcoseryl $2 \mathrm{ml}$ i.v., flunixine meglumine 1 $\mathrm{mg} / \mathrm{kg}$ i.m. Penicillin streptomycin 2 gm i.m., were administered for three days. Antitetanic serum (3000 IU) i.m., was injected. Animals were kept on reduced amount of green food and subjected to light exercise for half hour daily.

Vital parameters and blood samples were taken daily before induction of obstruction and before anastomosis as well as for 5 days after operation.

Twelve days after the operation, animals were euthanized by using over dose of thiopental sodium solution i.v.

After death of animals in group (I), they were subjected to post mortem examination to insure the complete closure of the duodenum. Samples were taken oral to the site of ligation and kept in $10 \%$ formalin for histopathological examination. In group (II), 12 days after the operation, animals were subjected to euthanasia and seat of anastomosis was taken for histopathological examination and preserved in $10 \%$ formalin.

Determination of blood parameters included the hmatological examination PCV, serum total protein, serum glucose, ALT, AST, BUN, creatinine and serum electrolytes (sodium, potassium, chloride, calcium and magnesium).

Statistical analysis (F- test and percentage of change) was performed according to (Snedecor and Cochran, 1976).

\section{Results}

Two to four hours after duodenal obstruction, teeth grinding, excessive salivation, mild to moderate abdominal pain, depression, decrease or absence of intestinal sound were observed in all animals. Finally the animal layed in recumbent lateral position and showed sluggish response to external stimuli. Animals of group I died after 22.37, 14.25, 21.44, 27.11 and 16.56 hours with a mean survival time of $20.35 \mathrm{~h}$ (Table 1).

The vital parameters included increased heart and respiratory rates with decreased body temperature and $\mathrm{pH}$ of gastric juice. Blood analysis revealed increased PCV, total protein, glucose, ALT, AST, BUN, serum creatinine, and potassium with decreased sodium, chloride, calcium, and magnesium (Table 2).

Animals treated by intestinal anastomosis (group II) were survived when surgical intervention was performed $14.35 \mathrm{~h}$ after obstruction. On the other hand animals treated at 16.35 and $18.35 \mathrm{~h}$ after obstruction died 12-48 $\mathrm{h}$ after the operation. The survived animals showed significant increase in the heart rate for 

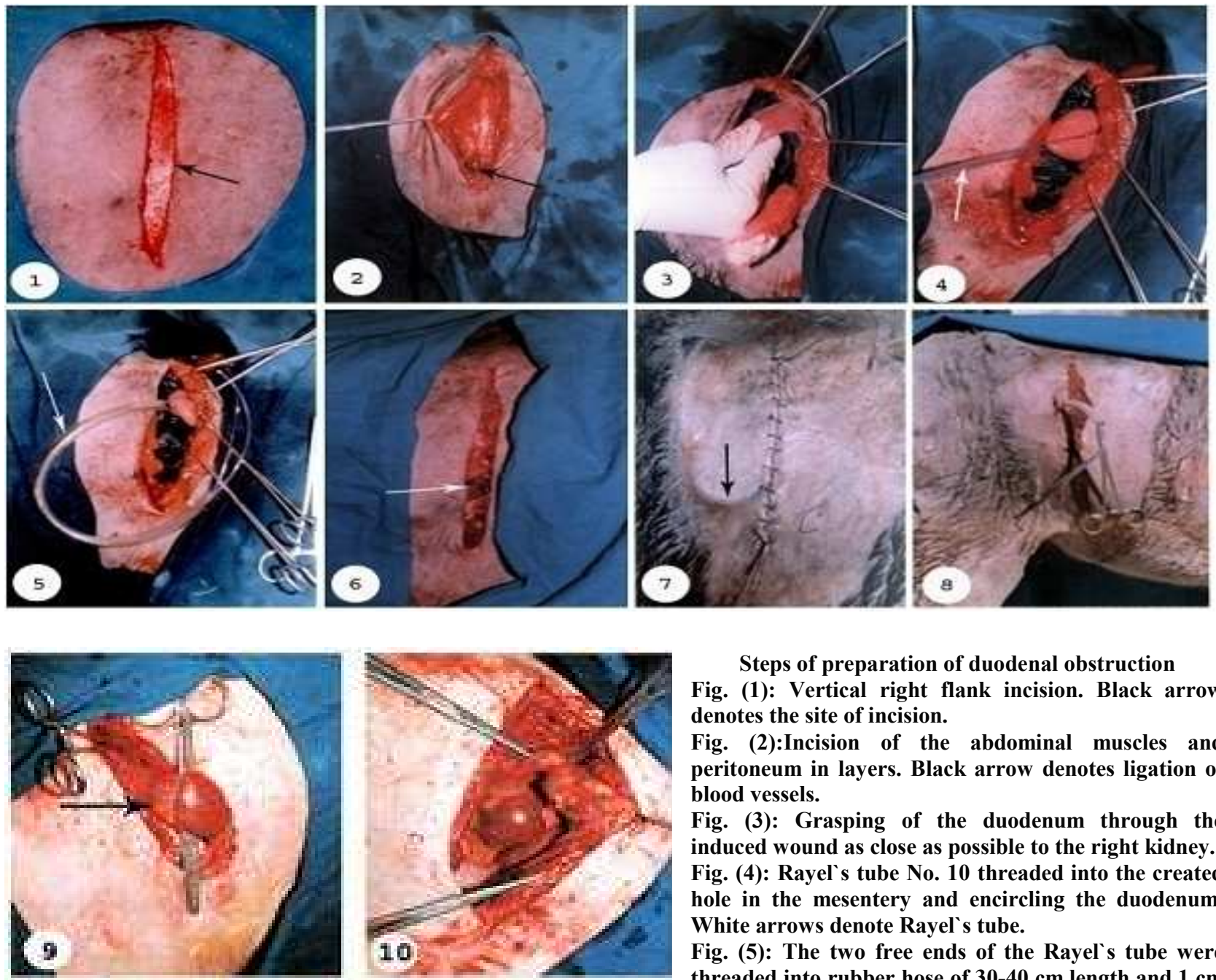

Steps of preparation of duodenal obstruction Fig. (1): Vertical right flank incision. Black arrow denotes the site of incision.

Fig. (2):Incision of the abdominal muscles and peritoneum in layers. Black arrow denotes ligation of blood vessels.

Fig. (3): Grasping of the duodenum through the induced wound as close as possible to the right kidney. Fig. (4): Rayel's tube No. 10 threaded into the created hole in the mesentery and encircling the duodenum. White arrows denote Rayel's tube.

Fig. (5): The two free ends of the Rayel's tube were threaded into rubber hose of 30-40 cm length and $1 \mathrm{~cm}$
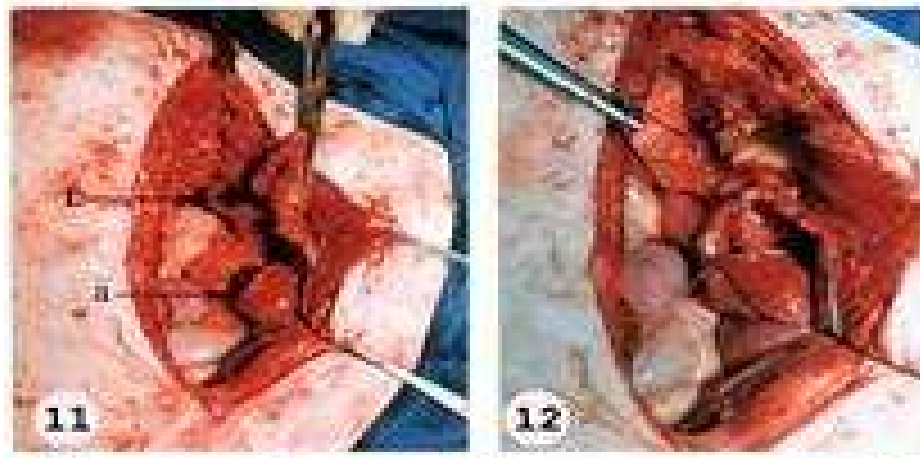
internal diameter. White arrows denote rubber hose.

Fig. (7): The skin was sutured by silk No. 2. Black arrow denotes the subcutaneous hose.

Fig. (6): Suturing of abdominal muscles with Rayel's tube passed through the muscular incision to be barred subcutaneously. White arrow denotes the Rayel's tube and hose.

Fig. (8): Rayel's tube was grasped against the hose to close the duodenum and the Rayel's was fixed to the hose by hemostatic forceps.

Steps of duodenal anastomosis

Fig. (9): Exteriorization of the duodenum and removal of Rayel's tube. Black arrow denotes the seat of
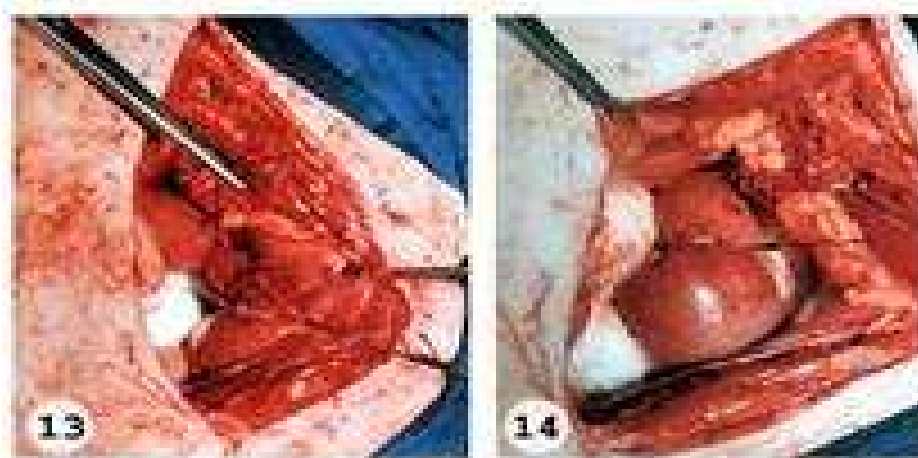

ligation.

Fig. (10): Ligation of the duodenum anterior and posterior to the seat of obstruction using silk No. 1 .

Fig. (11): Resection of a segment of the duodenum. (a) Oral segment of the duodenum. (b) Aboral segment of the duodenum.

Fig. (12): Apposition of the mesenteric and antimesenteric edges of the duodenum by two simple interrupted stitches.

Fig. (13): Single layer of simple interrupted sutures.

Fig. (14): Single layer of Cushing suture. Black arrow denotes line of anastomosis. 


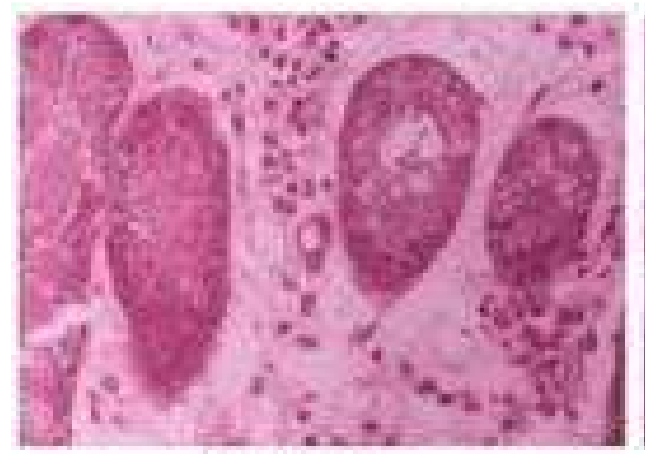

Fig. 15

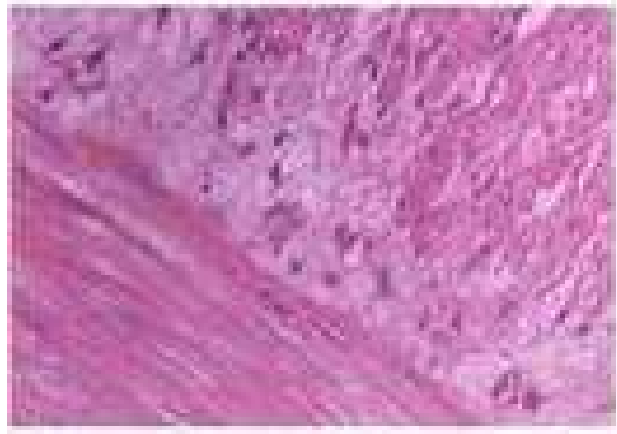

Fig. 17

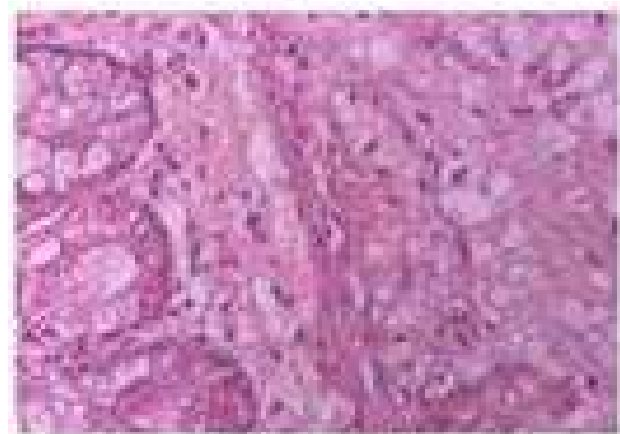

Fis. 19

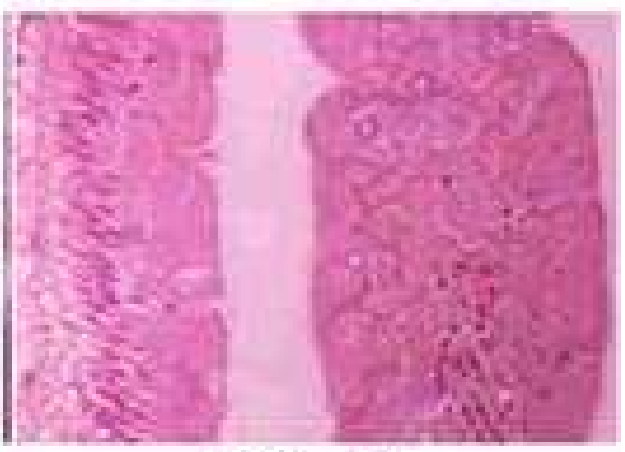

$F \lg =16$

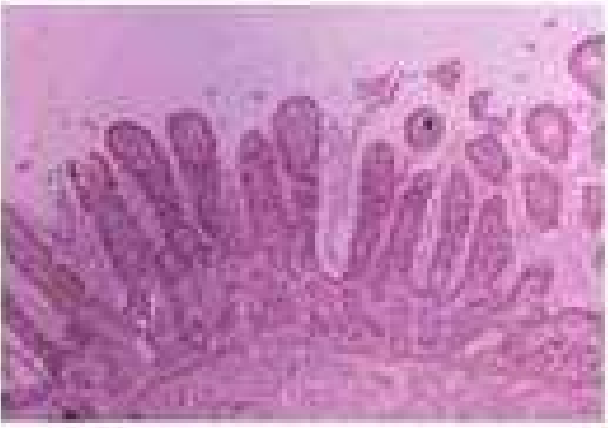

rig. 18

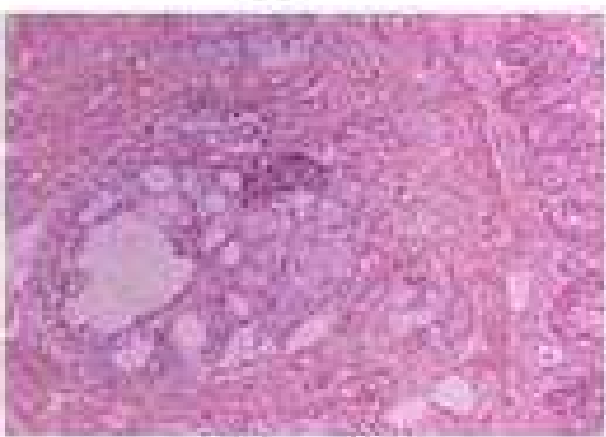

Fis. 20

Fig. (15): Duodenum, crypts showing severe necrotic changes (H\&E $x$ 400).

Fig. (16): Duodenum, villus epithelium - to the left, cells are more or less intact, to the right, severely affected epithelium (H\&E x 400).

Fig. (17): Duodenum, degenerating outer longitudinal and inner circular muscle fibers showing degeneration (H\&E x 400).

Fig. (18): Duodenum showing shortening of the intestinal villi (H\&E $x$ 40).

Fig. (19): Duodenum, necrotic changes of the mucosa and edema of the submucosa $(H \& E x$ 400).

Fig. (20): Duodenum, retention of Bruner's glands (H\&E x400).

2 days that became non-significant up to the $5^{\text {th }}$ day. Regarding the respiration rate there was no significant change during the obstruction period meanwhile there was significant decrease in the body temperature till the $4^{\text {th }}$ day after the operation.The results of hematological examination showed non-significant increase in PCV after ligation and non-significant decrease till the $5^{\text {th }}$ day. Moreover, the results revealed marked increase in the serum total protein, and glucose (after ligation), ALT, BUN (up to $2^{\text {nd }}$ day), and AST (up to $3^{\text {rd }}$ day). There was significant increase in creatinine after ligation while potassium and chloride showed high significant decrease after ligation with high significant decrease in magnesium extended to the $2^{\text {nd }}$ day. Sodium and calcium showed nonsignificant decrease after ligation. By the $5^{\text {th }}$ day, all parameters returned to its normal values (Table 3).

Histopathologicaly examination revealed crypts epithelial cells showed necrotic changes; 
Table (1): Mean survival time of animals with duodenal obstruction.

\begin{tabular}{ccccccc}
\hline Animals & A & B & C & D & E & Mean \\
\hline $\begin{array}{c}\text { Survival time in } \\
\text { hours }\end{array}$ & $22: 37$ & $14: 25$ & $21: 44$ & $27: 11$ & $16: 56$ & $20: 35$ \\
\hline
\end{tabular}

Table (2): Clinical and biochemical changes of animals with duodenal obstruction (Group I).

\begin{tabular}{|c|c|c|c|}
\hline Examined parameter & $\begin{array}{c}\text { Pre-obstruction } \\
\text { mean }\end{array}$ & $\begin{array}{c}\text { Peri-terminal } \\
\text { mean }\end{array}$ & $\%$ of change \\
\hline Heart rates (beats/ min) & 43.8 & 96.8 & $+121 \%$ \\
\hline Respiration rate resp/ min) & 18 & 33.8 & $+87.78 \%$ \\
\hline Body temperature $\left({ }^{\circ} \mathrm{C}\right)$ & 37.84 & 35.66 & $-5.76 \%$ \\
\hline Gastric juice pH & 6.4 & 3.4 & $-49.87 \%$ \\
\hline Packed cell volume (Vol. \%) & 29.4 & 39.8 & $+35.37 \%$ \\
\hline Serum total protein $(\mathrm{gm} / \mathrm{dl})$ & 6.13 & 9.84 & $+60.45 \%$ \\
\hline Serum glucose (mg/ dl) & 74.43 & 123.15 & $+65.46 \%$ \\
\hline Serum alanine aminotransferase (U/l) & 12.38 & 26.53 & $+114.26 \%$ \\
\hline Serum aspartate aminotransferase (U/l) & 55.2 & 116.71 & $+111.42 \%$ \\
\hline Blood urea nitorgen (mg/ dl) & 11.42 & 29.77 & $+160.73 \%$ \\
\hline Serum creatinine (mg/ dl) & 0.81 & 2.69 & $+231.28 \%$ \\
\hline Serum sodium ( $\mathrm{m} \mathrm{mol} / \mathrm{L})$ & 134.38 & 119.07 & $-11.39 \%$ \\
\hline Serum potassium $(\mathrm{m} \mathrm{mol} / \mathrm{L})$ & 3.59 & 3.83 & $+6.86 \%$ \\
\hline Serum chloride ( $\mathrm{m} \mathrm{mol} / \mathrm{L})$ & 103.35 & 77.64 & $-24.87 \%$ \\
\hline Serum calcium (mg/ dl) & 8.53 & 6.78 & $-20.52 \%$ \\
\hline Serum magnesium $(\mathrm{mg} / \mathrm{dl})$ & 2.09 & 1.65 & $-21.05 \%$ \\
\hline
\end{tabular}

Table (3): Clinical and biochemical changes of animals with duodenal obstruction and anastomosis (Group II).

\begin{tabular}{|c|c|c|c|c|c|c|c|}
\hline \multirow{2}{*}{$\begin{array}{l}\text { Examined } \\
\text { parameter }\end{array}$} & \multirow{2}{*}{$\begin{array}{l}\text { Time (h) } \\
\quad 0 \text { h }\end{array}$} & \multirow{2}{*}{$\begin{array}{c}14-35 \mathrm{~h} \\
\text { after } \\
\text { induction }\end{array}$} & \multicolumn{5}{|c|}{ Days after surgical intervention } \\
\hline & & & D 1 & D 2 & D 3 & D 4 & D 5 \\
\hline Heart rates & $43.33 \pm 3.51$ & $67 \pm 2 * *$ & $50.33 \pm 4.04 *$ & $50.67 \pm 6.03 *$ & $48 \pm 1$ & $45.33 \pm 4.04$ & $45 \pm 3.61$ \\
\hline Respiration rates & $18 \pm 1$ & $15.67 \pm 1.53$ & $20.67 \pm 5.03$ & $20.33 \pm 2.31$ & $19.67 \pm 1.53$ & $20.67 \pm 2.52$ & $19 \pm 1$ \\
\hline Body temperature & $38.43 \pm 0.25$ & $37.77 \pm 0.15 * *$ & $38.23 \pm 0.29$ & $38 \pm 0.17 *$ & $38.13 \pm 0.21$ & $38.03 \pm 0.06 *$ & $38.17 \pm 0.15$ \\
\hline Packed cell volume & $31.33 \pm 7.09$ & $36.67 \pm 7.64$ & $30.33 \pm 4.04$ & $30.67 \pm 4.72$ & $31 \pm 6.08$ & $30.67 \pm 5.67$ & $30 \pm 7.21$ \\
\hline Serum total protein & $6.82 \pm 0.38$ & $8.64 \pm 0.46 * *$ & $6.94 \pm 0.48$ & $6.95 \pm 0.38$ & $6.99 \pm 0.32$ & $6.94 \pm 0.28$ & $6.75 \pm 0.28$ \\
\hline Serum glucose & $70.42 \pm 6.37$ & $111.05 \pm 5.63^{* *}$ & $85.65 \pm 6.4$ & $71.53 \pm 13.42$ & $75.37 \pm 13.16$ & $78.47 \pm 13.4$ & $79.1 \pm 3.96$ \\
\hline ALT & $9.57 \pm 1.64$ & $20.88 \pm 1.56^{* *}$ & $17.41 \pm 1.13^{* *}$ & $13.53 \pm 0.92 * *$ & $12.81 \pm 1.4^{*}$ & $11.92 \pm 1.84$ & $10.62 \pm 0.75$ \\
\hline AST & $45.29 \pm 7.89$ & $76.97 \pm 2.58 * *$ & $71.59 \pm 1.64^{* *}$ & $67.39 \pm 2.71 * *$ & $58.89 \pm 4.78 * *$ & $52.64 \pm 6.73$ & $48.42 \pm 6.14$ \\
\hline BUN & $11 \pm 1.01$ & $20.99 \pm 3.11 * *$ & $19.32 \pm 3.05^{* *}$ & $16.21 \pm 1.68 * *$ & $14.53 \pm 0.71 *$ & $12.96 \pm 0.91$ & $11.36 \pm 0.45$ \\
\hline Serum creatinine & $0.79 \pm 0.05$ & $1.58 \pm 0.7 *$ & $1.43 \pm 0.61$ & $1.25 \pm 0.43$ & $1.07 \pm 0.25$ & $0.94 \pm 0.08$ & $0.83 \pm 0.05$ \\
\hline $\mathrm{Na}^{+}$ & $131.39 \pm 6.76$ & $124.06 \pm 6.25$ & $132.18 \pm 4.46$ & $133.96 \pm 4.43$ & $132.95 \pm 6.12$ & $131.88 \pm 5.8$ & $132.95 \pm 5.18$ \\
\hline $\mathbf{K}^{+}$ & $3.47 \pm 0.5$ & $2.7 \pm 0.18 * *$ & $3.48 \pm 0.12$ & $3.53 \pm 0.12$ & $3.49 \pm 0.15$ & $3.47 \pm 0.18$ & $3.5 \pm 0.14$ \\
\hline $\mathrm{Cl}^{-}$ & $101.86 \pm 3.08$ & $78.78 \pm 15.79 * *$ & $104.1 \pm 3.63$ & $105.4 \pm 3.32$ & $104.7 \pm 4.58$ & $103.94 \pm 4.58$ & $104.98 \pm 4.24$ \\
\hline $\mathrm{Ca}^{++}$ & $9.26 \pm 0.8$ & $8.57 \pm 0.56$ & $9.4 \pm 1.07$ & $9.43 \pm 0.97$ & $9.44 \pm 0.9$ & $9.47 \pm 0.92$ & $9.34 \pm 0.83$ \\
\hline $\mathbf{M g}^{++}$ & $1.7 \pm 0.04$ & $1.5 \pm 0.05 * *$ & $1.53 \pm 0.05 * *$ & $1.56 \pm 0.05 * *$ & $1.58 \pm 0.05^{*}$ & $1.62 \pm 0.06$ & $1.68 \pm 0.04$ \\
\hline
\end{tabular}


loosing their nuclei, leaving ghosts of cytolytic and disintegrated cells (Fig. 15). The villi showed degenerative and necrotic changes but to a lesser degree. Individual number of epithelial cells covering the villi appeared more or less intact with infiltration of mononuclear cells. The muscle bundles and fibres of muscularis mucosa in the inner circular and outer longitudinal layers were disintegrated. Many of the muscle fibers showed nuclear degeneration (Fig. 16). Browner's gland lying between muscularis mucosa were activated. The areolar connective tissue fibers of the submucosa were disorganized, dispersed and edematous. There was an increase in the inflammatory cells in the duodenal wall.

Histopathological examination of the anastomosed site revealed,the following; Essentially at both sides of the surgical anastomosis and around the line of junction, there was a shortening of the intestinal villi (Fig. 17). The thickness of the crypts was decreased. The intestine showed edema (Fig. 18) and formation of microscopical retention cysts of variable size originating most probably from Bruner's gland (Fig. 19). The cysts had a wall consisting of a single layer of epithelium and their lumens were empty. Lymph vessels in the wall were dilated (Fig. 20). Inflammatory changes, manifested by infiltration with leucocytes, subsided to a great extent.

\section{Discussion}

For experimental induction of simple duodenal obstruction, the modified technique of Datt and Usenik (1975) was used in the present study without complications from anesthesia or operation, as induction of obstruction was performed two weeks after operation without using anesthesia. All animals died with a mean survival time of $20 \mathrm{~h}$ and $35 \mathrm{~min}$. This was similar to that recorded by Datt and Usenik (1975). The low survival times of duodenal obstruction might be due to the short length of the gut cranial to the obstruction site, small volume of the stomach and the ability of the stomach to secrete continuously (Datt and Usenik, 1975).

The clinico-pathologic finding associated with intestinal obstruction might be due to the hypovolemic shock resulted from reduction in circulating blood volume, loss of total body water, increase in vascular permeability, inadequate perfusion of peripheral tissue, alteration in cellular metabolic pathway, and the generation of vasoactive no receptive substances
(White, 1990). As a result of hypovolemic shock, it was found that there was increase in the heart rate with low respiratory rate accompanied with reduction in the body temperature, after experimental induction of duodenal obstruction, (by Blood et al., 1995). On the other hand, Datt and Usenik, (1975) recorded elevation in the body temperature which may be attributed to excitement, pain, muscular exertion and inflammatory changes in the bowel wall.

Laboratory findings included increase of both the PCV and plasma total protein concentration as a result of continuous loss of fluid into the distended viscus (Snyder and Spier, 1996 and Moore, 1999) or the appreciable loss of water by the lung from hyperpenia and sweating (Datt and Usenik, 1975).

Serum electrolytes are rarely helpful in making a diagnosis but are helpful in calculating losses needed for treatment (White, 1990). Hypochloremia, hypokalemia, and hyponatremia were observed with duodenal obstruction. The same observations were reported by (Datt and Usenik, 1975; Snyder and Spier, 1996 and Spier et al., 1996). They mentioned that proximal obstruction of the duodenum resulted in rapid sequestration and loss of large amount of acidic gastric fluid (containing $\mathrm{H}+$ and $\mathrm{Cl}-$ ) with continuous absorption of alkaline pancreatic secretion leads to alkalosis with shifting of the extracellular potassium into intracellular space to exchange with hydrogen ions. Finally, reduction of chloride in the anion column occurs as a result of increased bicarbonate with reduction of sodium and potassium levels.

The recorded low level of calcium and magnesium was similar to that mentioned by (Datt and Usenik, 1975 and Helal, 2002) in donkeys.

It was found that serum glucose level was increased at terminal stage of obstruction, which may be due to release of endogenous substances as glucocorticoides as a result of pain, metabolic acidosis and inability of the cells to utilize glucose (Holbrook and Moore, 1996). This elevation emphasizes the importance of preventing incorporation of glucose in the fluid therapy to avoid its diuretic effect that aggravates the condition of animal dehydration (Bayly and Read, 1980).

The observed elevation in BUN and serum creatinine was attributed to the hypovolemia and renal ischemia that lower the urine flow rate with increased re-their absorption from the renal tubules (Spier et al., 1996 and Craig, 1998). 
The observed increase in AST activity rather than the ALT may be related to the hepatic hypoxic changes during hypovoleemia, increased vascular activity during colic and struggling as well as muscular ischemia (Meyer et al., 1992; Blood et al., 1995; Bud, 1997 and Craig, 1998).

The increased in survival rates for horses subjected to abdominal surgical operation may be attributed to earlier surgical intervention, operative technique and means of therapeutic management (Beroza, 1985).

Parks et al., (1989) mentioned that a positive correlation exists between an increase in the duration of clinical signs prior to surgical intervention and the mortality rate for horses that undergo surgery between 0-24 h after the onset of clinical signs i.e. there was a significant decrease in the survivors with increasing time between onset of clinical signs and presentation.

The result showed that all animals subjected to duodenal obstruction, survived when surgical intervention by intestinal resection and anastomosis were performed at $14.35 \mathrm{~h}$ after induction of obstruction. Delaying the time of surgical intervention decreased the percentage of survivors, as animals died within 12-48 hours post operation animals subjected to surgical intervention at 16.35 and $18.35 \mathrm{~h}$. The cause of death might be due to shock and irreversible changes at the wall of the obstructed part (Moore and white, 1982 and Youssef et al., 1992). Meanwhile Helal (2002) mention that the best time for surgical correction of ilial obstruction in donkeys was 10 hours.

Horses with acute abdominal disease require prompt medical therapy which includes analgesia, restoration of hydration and intestinal fluid balance, electrolytes and acid base balance, treatment of endotoxaemia and sepsis, as well as regulation of intestinal motility and transient of ingesta (White, 1990).

In this study, theraputic treatment after surgical resection and anastomosis includes ringer lactate i.v., analgesic and antitoxin (flunixine miglumin), protein free standardized dialystic of calf blood (solcoseryle), motility enhancing drugs (neostigmine methyl sulfate) to avoid paralytic ileus, antibiotic (penicillin streptomycin) brought the animals normal by the $5^{\text {th }}$ day .The level of serum electrolytes returned normal 1-2 days after intervention of fluid therapy. This agreed with (Spier et al., 1996 and Collatos and Morris, 1999).
The results of the histopathological investigation after obstruction revealed moderate degenerative changes to the mucosa and submucosa. These changes were probably caused by hypovolemia, cardiovascular collapse and shunting of the blood away from the splanchnic circulation (Grenger et al., 1980; Meschter et al., 1986; Snyder and Spier, 1996 and Dabareiner et al., 2001).

The degenerative changes reached the muscle fibers of the muscular layer might be due to the trauma inhibiting the contractility of the intestinal musculature especially the circular muscle layer. Dabareiner et al. (2001) mentioned that intestinal distention could produce damage that extends to the serosa. On the other hand luminal distention might increase intraabdominal pressure but still below the critical pressure able to produce intestinal injury (Smith, 1978; Snyder and Spier, 1996 and Moore, 1999).

It was found that healing after anastomosis despite the observed necrotic changes after obstruction might be due to the ability of mucosa to repair it-self via covering the denuded villus by the migrating enterocytes within 12-24 $\mathrm{h}$ (Snyder et al., 1989; White, 1990 and Moore, 1999).

\section{References}

Bayly, W. M. and Reed, S. M. (1980): Interpretation of clinicopathologic data in abdominal crises: II. Mod. Vet. Pract., 361-365.

Beroza, G. A.; Donawick, W. J. and Topkis, V. A. (1985): Intestinal decompression: preliminary study in the horse. Am. J. Vet. Med. Assoc., 186 (12): 1304-1309.

Blood, D. C.; Radostitis, O. M. and Gay, C. C. (1995): Veterinary Medicine, $8^{\text {th }}$ ed., Bailliere Tindal, pp. 157-240.

Bud, C. T. (1997): Hepatic function: In Kaneko, J. J.; John, W. H. and Michael, L. B. (ed): Clinical biochemistry of domestic animals. $5^{\text {th }}$ ed., Academic Press, pp. 327-352.

Collatos, C. and Morris, D. D. (1999): Fluid therapy: In Auer, A. J. and Stick, A. J. (ed): Equine surgery. $2^{\text {nd }}$ ed., W. B. Saunders Co., Philadelphia, London, pp: 3339.

Craig, A. L. (1998): Hepatic test abnormalities: In: Sunders manual of clinical laboratory science. W. B. Saunders Co., Philadelphia, London, Pp: 55-70.

Dabareiner, R. M.; Sullins, K. E.; White, N. A. and Snyder, J. R. (2001): Serosal injury in the equine jejunum and ascending colon after ischemia-reperfusion or intraluminal distention and decompression. Vet. Surg., 30: 114-125.

Datt, S. C. and Usenik, E. A. (1975): Intestinal obstruction in the horse. Cornell Vet. 65: 152-172.

Freeman, D. E. (1999): Small Intestine: In Auer, A. J. and Stick, A. J. (ed): Equine surgery. $2^{\text {nd }}$ ed., W. B. Saunders Co., Philadelphia, London, Pp: 232-256.

Grenger, D. N.; Kvietys, P. R. and Mortillaro, N. A. (1980): Effects of luminal distention on intestinal transcapillary fluid exchange. Am. J. Physiol., 239: G516523. 
Helal, I. E. M. (2002): Experimental induction of intestinal obstruction in equines with special reference to its surgical correction.

MVSc thesis, Dept. Surgery and Radiol. Fac. Vet. Med., Suez Canal Univ., Egypt.

Holbrook, T. C. and Moore, J. N. (1996): Pain: In Bradford, P. S. (ed): Large Animal Internal Medicine, $2^{\text {nd }}$ ed., copyright by Mosby, Pp: 27-34.

Meschter, C. L.; Tyler, D. E.; White, N. A. and Moore,

J. (1986): Histologic findings in the gastrointestinal tract of horses with colic. Am. J. Vet. Res., 47 (3): 598-606.

Meyer, D. J.; Coles, E. H. and Rich, L. J. (1992): Laboratory testes clinical enzymology: In Veterinary laboratory medicine interpretation and diagnosis, W. B. Saunders Co., Philadelphia, London, Toronto, Pp: 1-11.

Moore, J. N. and White, N. A. (1982): Acute abdominal disease. Vet. Clin. North. Am. Large Anim. Pract., 4: 61$78 .$.

Moore, R. M. (1999): Principles of intestinal injury and determining intestinal viability: In Auer, A. J. and Stick, A. J. (ed): Equine surgery, $2^{\text {nd }}$ ed., W. B. Saunders Co., Philadelphia, London, Pp: 189-306.

Morris, D. D. (1987): Medical management of equine colic Vet. Med., 158-172.

Snyder, J. R.; Pascoe, J. R.; Olander, H. J.; Spier, S. J.; Meagher, D. M. and Bleifer, D. R. (1989): Strangulating volvulus of the ascending colon in horse. Am. J. Vet. Med. Assoc., 195 (6): 757-764.

Parks, A. H.; Doran, R. E.; White, N. A.; Allen, D. and Baxter, G. M. (1989): Ileal impaction in the horse: 75 cases., Cornell Vet., 79: 83-91.
Smith, D. F. (1978): Presurgical care of the equine colic patient. Cornell Vet. 68 suppl., 7: 113-121.

Snedecor, G. W. and Cochran, W. G. (1976): Statistical Methods. $6^{\text {th }}$ ed., Ames, Iowa state press, USA.

Snyder, J. R. and Spier, S. J. (1996): Disorders of the small intestine associated with acute abdominal pain: In Bradford, P. S. (ed): Large animal internal medicine. $2^{\text {nd }}$ ed., copyright by Mosby Co, pp: 755-764.

Spier, S. J.; Snyder, J. R. and Murray, M. J. (1996): Fluid and electrolyte therapy for gastrointestinal disorders: In Bradford, P. S. (ed): Large animal internal medicine. $2^{\text {nd }}$ ed., copyright by Mosby Co., pp: 775-783.

Voughan, J. T. (1972): Surgical management of abdominal crisis in the horse.

J. Am. Vet. Med. Assoc., 161 (11): 1199-1212.

White, N. A. (1990): Pathophysiology and principles of therapy; pathophysiology of obstruction, strangulation and strangulation obstruction ischemia: In Colahan, P. T., Mayhew, I. G., Merritt, A. J. and Moore, J. N. (ed): Equine medicine and surgery. Goleta, CA, American Veterinary Publications (c), pp: 490.

White, N. A.; Moore, J. N. and Trim, C. M. (1980): Mucosal alterations in experimentally induced small intestinal strangulation obstruction in ponies. Am. J. Vet. Res., 41:193-198. .

Youssef, H. A.; Taha, M. M. and Ali, M. A. (1992): Pathologic changes associated with induced small and large intestinal strangulation in donkeys. $5^{\text {th }}$ sci. Conf., Fac. Vet Med. Assiut Univ., Egypt, pp. 167-172. 